\title{
Impact Assessment of Climate and Energy Policy Scenarios: A Multi-criteria Approach
}

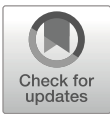

\author{
Hera Neofytou, Charikleia Karakosta, and Natalia Caldés Gómez
}

\begin{abstract}
Over the last 20 years, numerous studies have shown significant changes in the global climate which negatively affect life in many aspects. The perpetual problems due to climate change impacts have created the urgent need to find efficient ways to tackle them. In this frame, European countries are moving towards the creation of energy and climate policies in order to achieve specific targets and mitigate the consequences of greenhouse gas emissions. They have defined a number of scenarios comprised of different targets' combinations and ambition levels. The targets to be achieved are defined as to the $\mathrm{CO}_{2}$ emission reduction, the improvement in energy efficiency and the increase of the share of renewable energy sources until 2030. Thus, the aim is to lead EU to counteract the increasing energy demand and its negative effects on the environment as well as to abate the fossil fuel dependency. In this context, the scope of the particular paper is to examine which of the defined scenarios could respond adequately to the European region's profile and which could affect positively living conditions. Subsequently, the research focuses on the assessment of each alternative climate and energy policy scenario and its socioeconomic, environmental and energy impacts with the application of multi-criteria decision analysis. The method used in the herein analysis is the PROMETHEE II, which ranks the proposed scenarios based on the decisionmakers' preferences. In order to ensure the robustness of the results, a sensitivity analysis is also performed.
\end{abstract}

\footnotetext{
H. Neofytou ( $\square)$

Decision Support Systems Laboratory (EPU-NTUA), School of Electrical \& Computer Engineering, National Technical University of Athens, Athens, Greece e-mail: hneofytou@epu.ntua.gr

C. Karakosta

Decision Support Systems Laboratory (EPU-NTUA), School of Electrical \& Computer Engineering, National Technical University of Athens, Athens, Greece

Department of Industrial Management and Technology, University of Piraeus, Piraeus, Greece

N. C. Gómez

Department of Energy, Energy System Analysis Unit, CIEMAT, Madrid, Spain
} 
Keywords EU 2030 framework · Climate policy · Energy policy · Socioeconomic impacts · Environmental impacts · Energy impacts · Multi-criteria decision analysis · PROMETHEE

\section{Introduction}

Nowadays one of the most important and challenging problems is the climate change (EC 2017a). Health, environment and economy are affected directly by the climate change, and it is vital to seek solutions so as to counteract the rising dangers. At the same time, countries' growth and human activities increase the energy demand and the fossil fuel dependency, thus contributing to the increase of greenhouse gas (GHG) emissions. Several initiatives and agreements between countries have emerged to address the repercussions of climate change and carbon use, and some of them have already accomplished significant targets.

In industrialised countries, it is a great challenge to restructure consumption and production patterns into a low-carbon system. In 2014 the European Commission (EC) agreed upon a 2030 framework (EC 2014) for climate and energy policies including targets for $40 \%$ greenhouse gas reduction, $27 \%$ increase in the share of renewable energy sources (RES) and $27 \%$ increase in energy efficiency (EE) achievements, all compared to the 1990 levels. During the process of new measures' formulation, emphasis should be given in the methods employed, the impacts covered, the coverage of scenarios and the comparison of costs and benefits (De Bruyn and Warringa 2014) in order to ensure a safe, secure, sustainable and affordable energy for EU citizens (EC 2012).

International climate and energy policymaking is currently surrounded by many uncertainties. At the level of member state and EU-level policymakers, there is uncertainty about whether the EU climate and energy policy ambitions will eventually be matched by other countries' ambitions and whether the policy instruments and knowledge could be transferred to others. A process of decarbonising the EU economy will result in new economic opportunities for EU businesses, but it also requires that energy will increasingly be provided within the EU using renewable and biomass-based energy sources. This requires investments in secure energy systems, as well as social acceptance of different ways to supply and use energy (Flamos 2016; Papadelis et al. 2013).

In addition to the above, an impact assessment is important in order to ensure a sustainable development and since EU is obliged to conduct impact assessments of any new legislation before it is approved (EC 2009, 2017b). The impacts that would arise as a result of the implementation of a scenario are critical guidelines during the acceptance of policies between policymakers and the public (POLIMP 2012). For example, an energy policy scenario, apart from the direct impacts, such as energy savings, affects indirectly other sectors as well. It is possible that while some measures have positive consequences from a point of view, they also have negative, 
or less positive, results from another. In this sense it is important to strike a balance between the different levels and types of impacts (Streatfield and Markless 2009).

In this paper emphasis will be given to the socioeconomic, environmental and energy impacts that specific mitigation pathways evoke. These impacts have been proved to be key factors in achieving policy targets since they can affect the formulation of the measures to be adopted (TRANSrisk 2017). A variety of impact assessments have already been conducted but without concluding in one specific direction (Ernst and Young 2014; De Vos et al. 2014; Cambridge Econometrics 2013; POLIMP 2012).

The multi-criteria decision analysis (MCDA) has been developed and used to support the evaluation of different scenarios relying on their performance on several criteria under different assumptions (Ribeiro and Ferreira 2013). Hundreds of MCDA methodologies have been proposed (Loken 2007) and applied to a wide range of problems in the energy sector (Goumas and Lygerou 2000; Karakosta and Psarras 2012; Oskari et al. 2017; Papapostolou et al. 2017; Rahman et al. 2015; Volkart et al. 2017; Wang et al. 2009) as well as to explore alternative domestic energy and electricity policy scenarios (Browne et al. 2010). Policymakers need digestible information to design good policies and understand their options and the possible impacts of these options (Karakosta and Flamos 2016). It is towards this direction the herein study attempts to move.

The MCDA approach was selected here due to the fact that this method provides the flexibility and capacity to support the views of many decision-makers or stakeholders (Cherni et al. 2007) and has been applied to a wide range of energy sector's issues, such as for analysis of RES policy scenarios (Papapostolou et al. 2017), for the local energy planning (Marinakis et al. 2017), for energy efficiency measures in buildings (Doukas et al. 2016), as well as in many other decision-making problems (Karakosta and Askounis 2010; Papapostolou et al. 2016). On the other hand, there is a variety of papers that use socioeconomic, environmental and energy impacts in order to perform assessments of the new climate regime and of energy and climate targets (EC 2014; Ernst and Young 2014; De Bruyn and Warringa 2014; POLIMP 2012). To the best of our knowledge, there are only very few papers that deal with energy strategies combined with their socioeconomic, environmental and energy impacts (see Rahman et al. 2015). Thus, the added value of this study is the merging of a multi-criteria decision analysis - in order to assess climate and energy policy scenarios_-with their socioeconomic, environmental and energy impacts.

In particular, for the purposes of the herein work, one of the most efficient outranking methods was selected, the Preference Ranking Organization Method of Enrichment Evaluation (PROMETHEE) (Herva and Roca 2013; Kalogeras et al. 2005). PROMETHEE is closely coinciding with the human perspectives, and it determines the preferences among multiple decisions. It is also a suitable approach for an integrated analysis as its flexible algorithm can enable tailor-made enhancements to meet specific requirements for an integrated assessment approach, in particular, the explicit consideration of uncertainty information in the input values (Brans and Mareschal 2005; Kabir et al. 2014; Mohamadabadi et al. 2009). 
Given the complexity of the different design options, policymakers and stakeholders need a manageable tool to reduce this complexity. It should be mentioned that the tools which explore the climate change implications, as well as the models' outcomes regarding the cost and benefits, face a high degree of uncertainty. After all there are several mitigation pathways. On the other hand, the policies adapted in order to achieve the desirable socioeconomic, environmental and energy impacts hide many risks, which means that there is the possibility that the outcomes may differ from the expected ones. Risks include the potential damage that derives from uncertainty and the vulnerability to that damage. Towards this direction the study presents a methodology and a variety of criteria through which the risks and uncertainties could be taken into consideration and be addressed.

In this context, the aim of this paper is to evaluate the climate and energy policy scenarios in the EU region exploiting the available data of their environmental, social, economic and energy systems impacts. Examination and suggestion of the most beneficiary scenario in terms of living conditions' improvement have not yet been made using a MCDA and especially the PROMETHEE method. Consequently it is envisaged that this study may contribute to the effort of leading Europe to a low-carbon emission path considering the several implications the proposed actions may have.

The paper unfolds as follows: The second section elaborates the definition of the problem and is comprised of two subsections. The first one presents the proposed alternative actions of the problem which constitute the climate and energy policy scenarios. The second one regards the evaluation system including the definition of the criteria which are the impacts of the scenarios as well as the MCDA method to be used. The third section analyses how the PROMETHEE method for the evaluation of the actions and the Simos procedure for the definition of the criteria weights function, in other words the pilot application. In the last section, the conclusion of the analysis is provided.

\section{Defining the Problem}

The current situation in EU regarding climate and environment is quite unpropitious and constantly deteriorates creating an increasing number of serious problems. For that reason it is vital for Europe to seek and develop the appropriate climate and energy policies. In order to achieve climate and energy targets for 2030, the adoption of specific actions and measures, regarding emissions and energy management, is considered indispensable. The question is which of these actions and in what way may lead to the most sustainable solutions. The answer of this question will support the policy associated stakeholders to extract key policy conclusions.

As already mentioned, the aim of this paper is to evaluate and classify the abovementioned scenarios in order to be able to assess which one has longer positive 
effects on the living conditions in the European region. The evaluation will be based on the impacts each scenario has in different areas emphasising the social and economic ones.

\subsection{The Scenarios}

During the energy and climate policymaking process, multiple possible combinations and ambition levels may be considered. The European Commission (EC) has defined a number of scenarios regarding the achievement of 2030 targets, of which four representative scenarios have been chosen to be evaluated (plus the reference scenario). The basic characteristics of each scenario are presented below in brief (EC 2014).

Reference Scenario The EU Reference Scenario 2013 explores the consequences of current trends, including full implementation of policies adopted by late spring 2012.

GHG40 This scenario achieves GHG emission reductions by tightening the linear reduction factor in the ETS (EU 2015). It presents a medium ambition in terms of GHG emission reduction that meets by 2030 a $40 \%$ GHG reduction compared to 1990 levels. It is based on the assumption of equalisation of marginal abatement cost of GHG emissions across the economy driven by increasing carbon prices and simulated carbon values as described for scenario GHG37.

GHG40/EE This scenario presents a medium ambition in terms of GHG emission reduction and is mainly driven by explicit ambitious energy efficiency policies that ensure progress by addressing market imperfections and failures. Beyond concrete EE policies, carbon pricing incentivises fuel shifts, energy savings and nonenergyrelated emission reductions.

GHG40/EE/RES30 This scenario presents also a medium ambition in terms of GHG emission reduction and is mainly driven by explicit ambitious energy efficiency policies and pre-set RES target of 30\% that ensure progress by addressing market imperfections and failures. Beyond concrete EE policies, carbon pricing continues to incentivise fuel shifts, energy savings and nonenergy-related emission reductions. Moreover EE policies contribute to higher shares of RES as they reduce total energy consumption as well.

GHG45/EE/RES35 This scenario presents a high ambition in terms of GHG emission reduction and is mainly driven by explicit and very ambitious energy efficiency policies and pre-set RES target of 35\% that ensure progress by addressing market imperfections and failures. Beyond concrete EE policies, carbon pricing continues to incentivise fuel shifts, energy savings and nonenergy-related emission reductions.

In Table 1 an overview of the scenarios is provided. 
Table 1 Scenarios' overview

\begin{tabular}{|c|c|c|c|c|}
\hline & $\begin{array}{l}\text { Carbon } \\
\text { price } \\
(€ / \text { tonne) }\end{array}$ & $\begin{array}{l}\text { Ambition- } \\
\text { level EE } \\
\text { policies }\end{array}$ & $\begin{array}{l}\text { Ambition- } \\
\text { level RES } \\
\text { policies }\end{array}$ & Indicative policies employed \\
\hline Reference & 35 & $\begin{array}{l}2020 \\
\text { stand. }\end{array}$ & 2020 stand. & \\
\hline GHG40 & 40 & Moderate & Moderate & $\begin{array}{l}\text { Equalisation of increasing carbon prices } \\
\text { and values }\end{array}$ \\
\hline GHG40/EE & 22 & Ambitious & Moderate & $\begin{array}{l}\text { - Carbon pricing } \\
\text { - Speeding up the buildings' renovation } \\
\text { - Energy management systems } \\
\text { - Extended and more ambitious energy } \\
\text { efficiency obligations } \\
\text { - Eco-design regulations } \\
\text { - Smart grids }\end{array}$ \\
\hline $\begin{array}{l}\text { GHG40/EE/ } \\
\text { RES30 }\end{array}$ & 11 & Ambitious & $\begin{array}{l}30 \% \text { in } \\
2030\end{array}$ & $\begin{array}{l}\text { - Similar to those in GHG40/EE plus } \\
\text { - The average RES values rise from } \\
49 € / \mathrm{MWh} \text { in } 2020 \text { to } 56 € / \mathrm{MWh} \text { in } \\
2030 \text { and decline to } 36 € / \mathrm{MWh} \text { in } 2050\end{array}$ \\
\hline $\begin{array}{l}\text { GHG45/EE/ } \\
\text { RES35 }\end{array}$ & 14 & Ambitious & $\begin{array}{l}35 \% \text { in } \\
2030\end{array}$ & Similar to those in GHG40/EE/RES30 \\
\hline
\end{tabular}

\subsection{The Multi-criteria Evaluation System}

\subsubsection{The Criteria}

A multi-criteria evaluation model is proposed for the assessment of the different scenarios that could reach Europe's 2030 targets. It comprises 12 evaluation criteria based on four evaluation points of view to support decisions in selecting the most suitable scenario for the previous description (Fig. 1):

1. Environmental impacts

2. Social impacts

3. Economic impacts

4. Energy systems impacts

The evaluation criteria and model were selected after an extensive literature review (Cambridge Econometrics 2013; De Vos et al. 2014; Ernst and Young 2014; POLIMP 2012) and with the support of a panel of experts with experience in the climate and energy sectors (Karakosta et al. 2008; Karakosta and Askounis 2010; Papapostolou et al. 2017), in an attempt to cover all the different aspects.

The definition of criteria is presented below (EC 2014).

GHG reductions vs. 1990 (g1) This criterion is a percentage that indicates the total amount of greenhouse gas reduction in the ETS and non-ETS sectors compared to the respective emissions in 1990. 


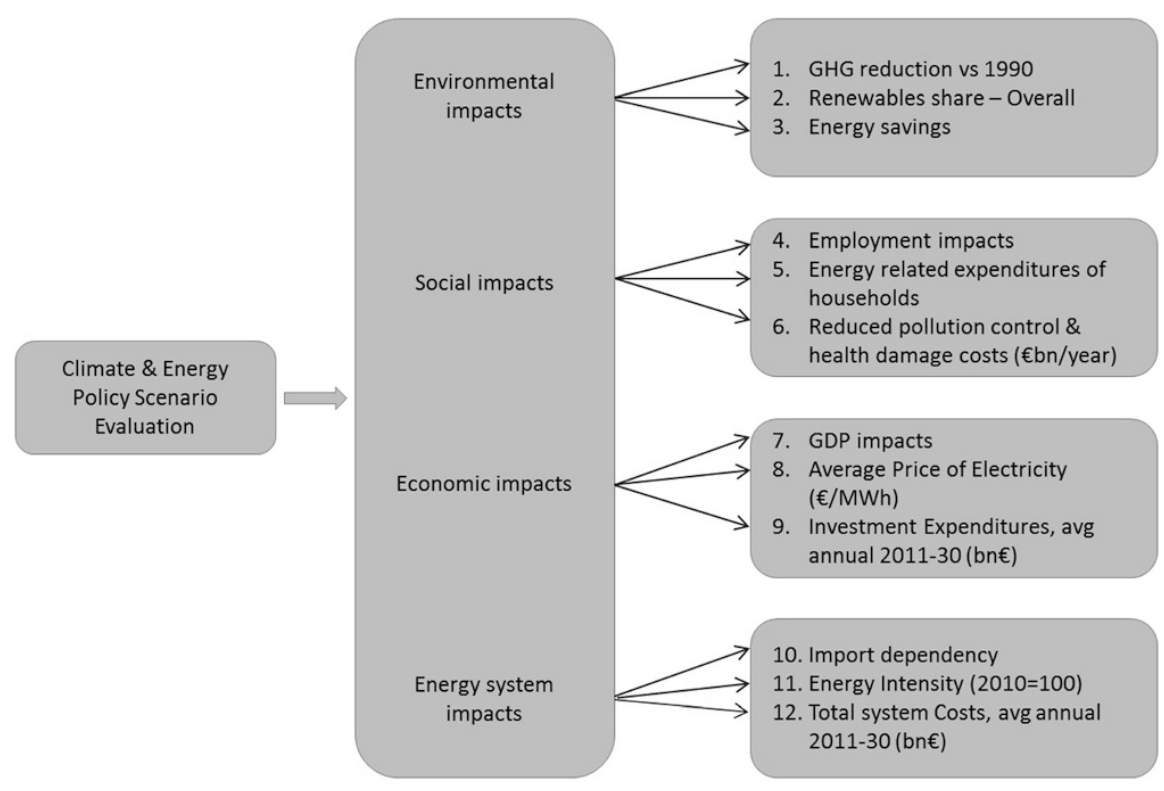

Fig. 1 Evaluation points of view and criteria

Renewable Share: Overall (g2) This criterion represents the share of energy from renewable sources (e.g. electricity, energy for heating and cooling and energy in transportation) in gross final energy consumption.

Energy Savings (g3) This percentage shows how much less primary energy will be consumed compared to projections made in 2007 for the 2030 as a result of the implementation of proposed measures of the scenarios and not of a decrease of GDP.

Employment Impacts (g4) This number indicates the total number of employees in all the sectors such as agriculture, extraction industries, basic manufacturing, engineering and transport equipment, utilities, construction, distribution and retail, transport, communication and publishing, business services and public services.

Energy-Related Expenditures of Households (g5) This number stands for the share of energy-related expenditures of households (referring to stationary uses) in average household expenditure. For the Reference Scenario, the corresponding value was $7.5 \%$ in 2010 .

Reduced Pollution Control and Health Damage Costs (€bn/year) (g6) The reduction in air pollution has positive impacts on human health. The number of life year lost is being reduced due to lower harmful emissions' concentrations. The reduction in mortality can also be valued economically. Because of lower emissions and air pollution, costs to control them are lower as well. Consequently this index shows the monetary reduction of health damage costs due to reduced air pollution compared to the Reference Scenario. Valuation uses value of life year lost used for the Thematic Strategy on Air Pollution, ranging 57,000-133,000 € per life year lost. 
GDP Impacts (g7) Gross domestic product (GDP) is a monetary measure of the market value of all final goods and services produced in a period. This criterion represents how much the GDP will change in comparison with the Reference Scenario.

Average Price of Electricity $(\boldsymbol{E} / \mathbf{M W h})(\mathbf{g 8})$ This criterion presents the price of electricity in the final demand sectors with constant the 2010 Euro's value.

Investment Expenditures, Annual 2011-2030 (bn€) (g9) Direct efficiency investment costs include costs for house insulation, double/triple glazing, control systems, energy management and for efficiency enhancing changes in production processes not accounted for under energy capital and fuel/electricity purchase costs. They also include the cost for the transport equipment. They regard the industry sector; residential and tertiary sector; transport, grid and generation; and boilers.

Import Dependency (g10) Import dependency indicates the share of net imports to primary energy consumption.

Energy Intensity $(\mathbf{2 0 1 0}=\mathbf{1 0 0})(\mathbf{g 1 1})$ Energy intensity is the ratio between the gross inland energy consumption (GIEC) and gross domestic product (GDP) calculated for a calendar year. GIEC is calculated as the sum of the gross inland consumption of the five sources of energy: solid fuels, oil, natural gas, nuclear and renewable sources. To monitor trends, GDP is in constant prices to avoid the impact of inflation, with a base year of 2010 (EEA 2016). Gross inland energy consumption is measured in 1000 tonnes of oil equivalent (ktoe), while GDP is expressed in million Euros at 2010 market prices. To make comparisons of trends across countries more meaningful, the indicator is presented as an index.

Total System Costs, Avg Annual 2011-2030 (bn€) (g12) Energy system costs from an end user perspective as calculated in the modelling comprise mainly three elements: annuities for capital expenditure on energy using equipment (for energy installations such as power plants and energy infrastructure, energy using equipment, appliances and vehicles); fuel and electricity costs, including the capital expenditure for the production and distribution of electricity; and so-called direct energy efficiency costs incurred (not related to energy equipment itself), such as expenditure for insulation. Capital costs are expressed in annuity payments.

The preference value of each criterion is given in Table 2 .

\subsubsection{The PROMETHEE Method}

PROMETHEE (Preference Ranking Organization METHod for Enrichment Evaluation) is an outranking method, developed by Brans et al. (1986), which is used when someone has to decide which action is better compared to others. Its main characteristic is the pairwise comparison using the inner relationships of each pair of actions based on the respective weights. PROMETHEE I (obtained from the positive and negative outranking flows) is used in cases where only a partial ranking is 
Table 2 Criteria preferences

\begin{tabular}{l|l}
\hline Criterion & Preference \\
\hline$g_{1}$ & Max \\
\hline$g_{2}$ & Max \\
\hline$g_{3}$ & Max \\
\hline$g_{4}$ & Max \\
\hline$g_{5}$ & Min \\
\hline$g_{6}$ & Max \\
\hline$g_{7}$ & Max \\
\hline$g_{8}$ & Min \\
\hline$g_{9}$ & Min \\
\hline$g_{10}$ & Min \\
\hline$g_{11}$ & Min \\
\hline$g_{12}$ & Min \\
\hline
\end{tabular}

needed, whereas PROMETHEE II (based on the net preference flow) is used for complete ranking of the alternatives (Brans et al. 1986).

The application of the method includes five steps:

1. Determination of the criteria weights, $w_{j}$, using the preferable method. The decision-maker has to define the weights so as to counterbalance the importance of each alternative. The sum of these weights has to equal the unit: $\sum w_{j}=1$. The methodology used for the calculation of the weights is presented in Sect. 2.2.3.

2. Determination of a particular preference function in order to translate deviation between the evaluations of two alternatives $(a$ and $b)$ on a specific criterion $\left(g_{j}\right)$ into a preference degree. Each criterion has a preference function:

$$
P_{j}(a, b)=F_{j}\left[d_{j}(a, b)\right]
$$

where $F_{j}$ is a non-decreasing function of the observed deviations $d_{j}$ and $d_{j}(a$, $b)=g_{j}(a)-g_{j}(b)$

The larger the deviation, the larger the preference ( 0 for no preference, 1 for strict preference). If $d_{j} \leq 0$, then $P_{j}(a, b)=0$; in other case the analyst should choose between multiple types: usual, U shape, $\mathrm{V}$ shape, level, linear and Gaussian. Some extra parameters may be used such as indifference threshold or preference threshold in case of using any type of the function except the usual.

3. Calculation of global preference index $\pi(a, b)$ which represents the intensity of preference of alternative $a$ over $b$ taking the weights into account:

$$
\pi(a, b)=\sum_{j=1}^{n} P_{j}(a, b) w_{j}
$$

where $P_{j}(a, b)$ is the preference function and $w_{j}$ represents the weight of each criterion. 
4. Calculation of outranking flows. Positive outranking flow $\varphi^{+}(a)$ and negative outranking flow $\varphi^{-}(b)$ measure how much the alternative a is outranking or outranked by the other alternatives:

$$
\begin{aligned}
\varphi^{+}(a) & =\frac{1}{n-1} \sum_{b} \pi(a, b) \\
\varphi^{-}(a) & =\frac{1}{n-1} \sum_{b} \pi(b, a)
\end{aligned}
$$

5. Calculation of the net outranking flow. Finally, in order to rank actions completely, the net outranking flow $\varphi(a)$ is determined using the equation below:

$$
\varphi(\alpha)=\varphi^{+}(a)-\varphi^{-}(a)
$$

\subsubsection{Simos Procedure}

As mentioned above, the first thing analyst has to determine is the criteria weights. The method followed in this paper is the Simos procedure, as an adequate aggregation procedure, where the decision-maker (DM) is able to hierarchise the criteria given a specific context. The gist of this method is that it correlates each criterion with one "card". The DM has to rank the criteria managing the respective cards from the least important to the most important and inserting "white cards" in order to make the distance between them larger if he wants to point out the differences between their importance. No white card means that the criteria have not the same weight and that the difference between the weights can be chosen as the unit for measuring the intervals between weights. Let us denote this unit. One white card means a difference of two times u. Two white cards mean a difference of three times u, etc. (Figueira and Roy 2002; Simos 1990).

\section{Pilot Application and Scenario Analysis}

In this section the collected data is presented and subsequently the results from the application of the PROMETHEE method.

The values of the criteria for each alternative are presented in Tables 3 and 4 (EC 2014).

During the application of a MCDA method, one has to keep in mind that there are no universal best solutions since results derive upon personal judgement of different criteria (Ribeiro and Ferreira 2013). The general approach was to request several 
Table 3 Climate and energy policy scenario impacts (a)

\begin{tabular}{l|l|l|l|l|l|l}
\hline $\begin{array}{l}\text { Climate and energy policy } \\
\text { scenarios }\end{array}$ & $g_{1}(\%)$ & $g_{2}(\%)$ & $g_{3}(\%)$ & $g_{4}$ & $g_{5}(\%)$ & $g_{6}$ \\
\hline Reference & -32.40 & 24.40 & -21.00 & $231,781,000$ & 9.30 & 0.00 \\
\hline GHG40 & -40.60 & 26.50 & -25.10 & $232,379,000$ & 9.40 & 10.35 \\
\hline GHG40EE & -40.30 & 26.40 & -29.30 & $232,132,000$ & 9.50 & 26.10 \\
\hline GHG40EERES30 & -40.70 & 30.30 & -30.10 & $232,514,000$ & 9.40 & 24.95 \\
\hline GHG45EERES35 & -45.10 & 35.40 & -33.70 & $232,075,000$ & 9.70 & 31.70 \\
\hline
\end{tabular}

Table 4 Climate and energy policy scenario impacts (b)

\begin{tabular}{l|r|l|l|l|l|l}
\hline Climate and energy policy scenarios & $g_{7}(\%)$ & $g_{8}$ & $g_{9}$ & $g_{10}(\%)$ & $g_{11}$ & $g_{12}$ \\
\hline Reference & 0.00 & 176 & 816 & 55.10 & 67 & 2,067 \\
\hline GHG40 & -0.28 & 179 & 854 & 53.60 & 64 & 2,069 \\
\hline GHG40EE & 0.55 & 174 & 875 & 52.80 & 60 & 2,089 \\
\hline GHG40EERES30 & 0.46 & 178 & 879 & 51.80 & 60 & 2,089 \\
\hline GHG45EERES35 & 0.53 & 196 & 909 & 52.30 & 57 & 2,102 \\
\hline
\end{tabular}

experts (DMs) to rank these criteria in order to perform a sensitivity analysis. In this context, eight experts, one governmental representative, two energy experts, one from the civil society, one from NGO, one from the scientific community, one from the industry and one from the general public were asked to use the SIMOS procedure and hierarchise the criteria, thus exporting four slightly different weights for each one. The weights that derived from this procedure are presented for each expert in Table 5.

Moreover, the analyst chose to use the preference function of usual type for every single criterion since there aren't any thresholds. This function serves to transform deviations into 0 or 1 in case $a$ is not preferable from $b$ and $a$ is preferable from $b$, respectively. The preference function is calculated for each criterion (impacts) and all pairs of the alternative actions (policy scenarios) (Eq. 1) and used to calculate the preference index given in (Eq. 2). The final step is to calculate the net outranking flow (Eq. 5) using the positive and negative outranking flows (Eqs. 3 and 4).

For the implementation of the procedure, the Visual PROMETHEE [http://www. promethee-gaia.net/software.html] was used which provides numerical as well as visual results. Thus, inserting all the data and parameters, the programme exports the results based on the perspective of each expert (Table 6).

The alternative scenarios have been ranked using the net outranking flow that varies between -1 and 1, which is presented in Fig. 2 .

Observing the comparison of the scenarios, it is obvious that, in all cases, the fifth and the fourth places are taken by the Reference and the GHG40 scenarios, respectively. This result was expected since the Reference Scenario does not include any measures to further contribute to the greenhouse gases' reduction or to increase the RES; and the GHG40 includes limited and very specific actions mainly for the greenhouse gases' reduction, and it does not enhance any other aspect of life. 
Table 5 Criteria weights per expert

\begin{tabular}{|c|c|c|c|c|c|c|c|c|}
\hline Criteria & $\begin{array}{l}\text { Exp. } \\
1\end{array}$ & $\begin{array}{l}\text { Exp. } \\
2\end{array}$ & $\begin{array}{l}\text { Exp. } \\
3\end{array}$ & $\begin{array}{l}\text { Exp. } \\
4\end{array}$ & $\begin{array}{l}\text { Exp. } \\
5\end{array}$ & $\begin{array}{l}\text { Exp. } \\
6\end{array}$ & $\begin{array}{l}\text { Exp. } \\
7\end{array}$ & $\begin{array}{l}\text { Exp } \\
8\end{array}$ \\
\hline GHG reductions vs. $1990(g 1)$ & 0.14 & 0.15 & 0.10 & 0.14 & 0.15 & 0.15 & 0.15 & 0.04 \\
\hline Renewables share-overall $(g 2)$ & 0.07 & 0.07 & 0.06 & 0.09 & 0.08 & 0.01 & 0.02 & 0.08 \\
\hline Energy savings $(g 3)$ & 0.07 & 0.07 & 0.06 & 0.11 & 0.08 & 0.14 & 0.10 & 0.08 \\
\hline Employment impacts $(g 4)$ & 0.14 & 0.15 & 0.14 & 0.14 & 0.13 & 0.12 & 0.13 & 0.05 \\
\hline $\begin{array}{l}\text { Energy-related expenditures } \\
\text { of households }(g 5)\end{array}$ & 0.12 & 0.11 & 0.14 & 0.11 & 0.13 & 0.13 & 0.15 & 0.02 \\
\hline $\begin{array}{l}\text { Reduced pollution control and } \\
\text { health damage costs }(g 6)\end{array}$ & 0.14 & 0.11 & 0.14 & 0.06 & 0.10 & 0.10 & 0.05 & 0.11 \\
\hline GDP impacts $(g 7)$ & 0.10 & 0.11 & 0.14 & 0.11 & 0.10 & 0.06 & 0.07 & 0.16 \\
\hline $\begin{array}{l}\text { Average price of } \\
\text { electricity }(g 8)\end{array}$ & 0.10 & 0.11 & 0.14 & 0.11 & 0.13 & 0.09 & 0.11 & 0.06 \\
\hline $\begin{array}{l}\text { Investment expenditures, annual } \\
2011-2030(g 9)\end{array}$ & 0.02 & 0.03 & 0.02 & 0.06 & 0.02 & 0.04 & 0.11 & 0.02 \\
\hline Import dependency $(g 10)$ & 0.02 & 0.03 & 0.02 & 0.02 & 0.04 & 0.04 & 0.05 & 0.14 \\
\hline Energy intensity $(g 11)$ & 0.04 & 0.03 & 0.02 & 0.02 & 0.04 & 0.04 & 0.02 & 0.14 \\
\hline $\begin{array}{l}\text { Total system costs, avg annual } \\
2011-2030(g 12)\end{array}$ & 0.02 & 0.03 & 0.02 & 0.02 & 0.02 & 0.08 & 0.02 & 0.11 \\
\hline
\end{tabular}

As for the first place, the prevailing scenario is the GHG40EERES30 in all cases except for the last one, since the expert is a governmental representative. This means that criteria like GDP, import dependency, energy intensity, reduced pollution control and health damage costs and system costs had the highest weights, while energy-related expenditures of households, investment expenditures and GHG reductions had the lowest.

The remaining scenarios, the GHG45RES35 and the GHG40EE, are switched between the second and the third places with the GHG45RES35 taking the second place in five out of the seven cases. The case where the GHG40RES35 takes the third place is when the experts ( 3 and 7 ) lent weight to criteria for which this scenario presents the worst numbers. More specifically, it seems that these two experts overrate the importance of energy-related expenditures and average price of electricity. This could be explained somehow since the experts originate from the energy sector.

Sensitivity analysis shows that the prevailing ranking is:

- GHG40EERES30

- GHG45EERES35

- GHG40EE

- GHG40

- Reference 


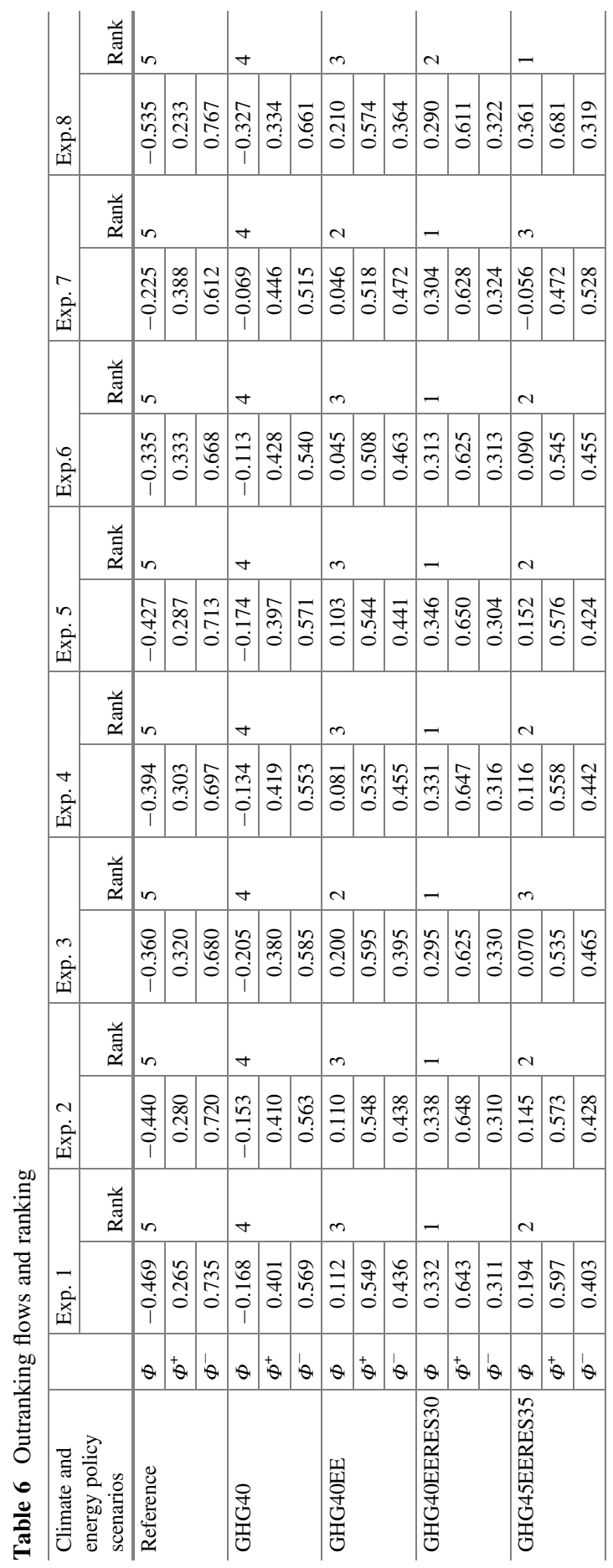




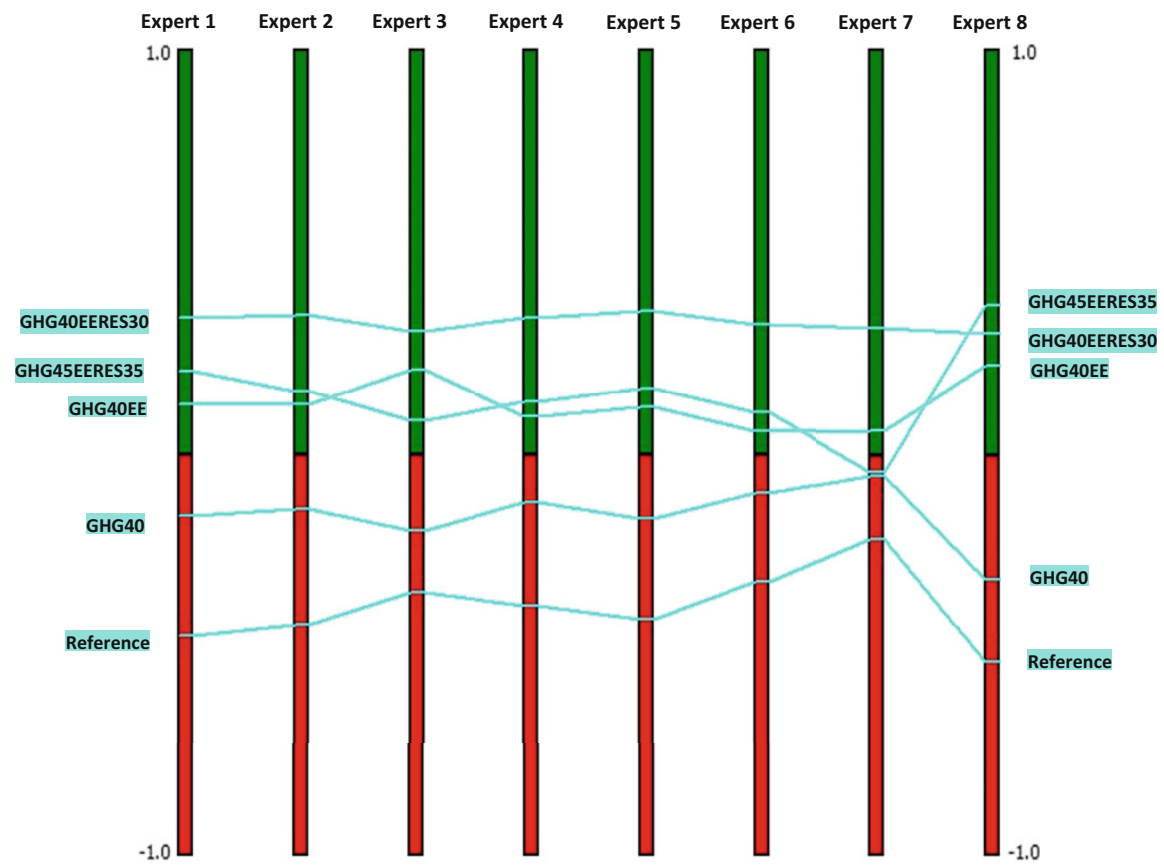

Fig. 2 Comparison of scenario ranking

Table 7 Distances between scenarios for Expert 1

\begin{tabular}{l|l|l|l|l|l}
\hline Exp. 1 & GHG40EERES30 & GHG45EERES35 & GHG40EE & GHG40 & Reference \\
\hline GHG40EERES30 & & -0.14 & -0.22 & -0.50 & -0.80 \\
\hline GHG45EERES35 & 0.14 & & -0.08 & -0.36 & -0.66 \\
\hline GHG40EE & 0.22 & 0.08 & & -0.28 & -0.58 \\
\hline GHG40 & 0.50 & 0.36 & 0.28 & & -0.30 \\
\hline Reference & 0.80 & 0.66 & 0.58 & 0.30 & \\
\hline
\end{tabular}

Negative value means that the scenario on the vertical axis is considered worse (lower in the PROMETHEE ranking) than that on the horizontal axis

In order to verify the above outcome, a further analysis was conducted, which indicated to what degree a specific scenario is better or worse compared to the others. To illustrate this, the distances between the scenarios were calculated as well as the respective averages, and the results showed the degree of preference or not preference between each pair of them (Tables 7, 8, 9, 10,11,12, 13 and 14).

The average distances between the scenarios are provided in Table 15. As it can be easily conceived, this analysis's results coincide with the above sensitivity analysis since in the first column the values (distances from the GHG40EERES30) are increasing, as we move to the Reference Scenario and thus the same ranking like the previous derives. 
Table 8 Distances between scenarios for Expert 2

\begin{tabular}{l|l|l|l|l|l}
\hline Exp. 2 & GHG40EERES30 & GHG45EERES35 & GHG40EE & GHG40 & Reference \\
\hline GHG40EERES30 & & -0.19 & -0.23 & -0.49 & -0.78 \\
\hline GHG45EERES35 & 0.19 & & -0.04 & -0.30 & -0.59 \\
\hline GHG40EE & 0.23 & 0.04 & & -0.26 & -0.55 \\
\hline GHG40 & 0.49 & 0.30 & 0.26 & & -0.29 \\
\hline Reference & 0.78 & 0.59 & 0.55 & 0.29 & \\
\hline
\end{tabular}

Negative value means that the scenario on the vertical axis is considered worse (lower in the PROMETHEE ranking) than that on the horizontal axis

Table 9 Distances between scenarios for Expert 3

\begin{tabular}{l|l|l|c|l|l}
\hline Exp. 3 & GHG40EERES30 & GHG45EERES35 & GHG40EE & GHG40 & Reference \\
\hline GHG40EERES30 & & -0.23 & -0.10 & -0.50 & -0.66 \\
\hline GHG45EERES35 & 0.23 & & 0.13 & -0.28 & -0.43 \\
\hline GHG40EE & 0.10 & -0.13 & & -0.41 & -0.56 \\
\hline GHG40 & 0.50 & 0.28 & 0.41 & & -0.16 \\
\hline Reference & 0.66 & 0.43 & 0.56 & 0.16 & \\
\hline
\end{tabular}

Negative value means that the scenario on the vertical axis is considered worse (lower in the PROMETHEE ranking) than that on the horizontal axis

Table 10 Distances between scenarios for Expert 4

\begin{tabular}{l|l|l|l|l|l}
\hline Exp. 4 & GHG40EERES30 & GHG45EERES35 & GHG40EE & GHG40 & Reference \\
\hline GHG40EERES30 & & -0.22 & -0.25 & -0.47 & -0.73 \\
\hline GHG45EERES35 & 0.22 & & -0.04 & -0.25 & -0.51 \\
\hline GHG40EE & 0.25 & 0.04 & & -0.22 & -0.48 \\
\hline GHG40 & 0.47 & 0.25 & 0.22 & & -0.26 \\
\hline Reference & 0.73 & 0.51 & 0.48 & 0.26 & \\
\hline
\end{tabular}

Negative value means that the scenario on the vertical axis is considered worse (lower in the PROMETHEE ranking) than that on the horizontal axis

Table 11 Distances between scenarios for Expert 5

\begin{tabular}{l|l|l|l|l|l}
\hline Exp. 5 & GHG40EERES30 & GHG45EERES35 & GHG40EE & GHG40 & Reference \\
\hline GHG40EERES30 & & -0.19 & -0.24 & -0.52 & -0.77 \\
\hline GHG45EERES35 & 0.19 & & -0.05 & -0.33 & -0.58 \\
\hline GHG40EE & 0.24 & 0.05 & & -0.28 & -0.53 \\
\hline GHG40 & 0.52 & 0.33 & 0.28 & & -0.25 \\
\hline Reference & 0.77 & 0.58 & 0.53 & 0.25 & \\
\hline
\end{tabular}

Negative value means that the scenario on the vertical axis is considered worse (lower in the PROMETHEE ranking) than that on the horizontal axis 
Table 12 Distances between scenarios for Expert 6

\begin{tabular}{l|l|l|l|l|l}
\hline Exp. 6 & GHG40EERES30 & GHG45EERES35 & GHG40EE & GHG40 & Reference \\
\hline GHG40EERES30 & & -0.22 & -0.27 & -0.43 & -0.65 \\
\hline GHG45EERES35 & 0.22 & & -0.05 & -0.20 & -0.43 \\
\hline GHG40EE & 0.27 & 0.05 & & -0.16 & -0.38 \\
\hline GHG40 & 0.43 & 0.20 & 0.16 & & -0.22 \\
\hline Reference & 0.65 & 0.43 & 0.38 & 0.22 & \\
\hline
\end{tabular}

Negative value means that the scenario on the vertical axis is considered worse (lower in the PROMETHEE ranking) than that on the horizontal axis

Table 13 Distances between scenarios for Expert 7

\begin{tabular}{l|l|l|l|l|l}
\hline Exp. 7 & GHG40EERES30 & GHG45EERES35 & GHG40EE & GHG40 & Reference \\
\hline GHG40EERES30 & & -0.36 & -0.26 & -0.37 & -0.53 \\
\hline GHG45EERES35 & 0.36 & & 0.10 & -0.01 & -0.17 \\
\hline GHG40EE & 0.26 & -0.10 & & -0.12 & -0.27 \\
\hline GHG40 & 0.37 & 0.01 & 0.12 & & -0.16 \\
\hline Reference & 0.53 & 0.17 & 0.27 & 0.16 &
\end{tabular}

Negative value means that the scenario on the vertical axis is considered worse (lower in the PROMETHEE ranking) than that on the horizontal axis

Table 14 Distances between scenarios for Expert 8

\begin{tabular}{l|c|l|l|l|l}
\hline Exp. 8 & GHG40EERES30 & GHG45EERES35 & GHG40EE & GHG40 & Reference \\
\hline GHG40EERES30 & & 0.07 & -0.08 & -0.62 & -0.83 \\
\hline GHG45EERES35 & -0.07 & & -0.15 & -0.69 & -0.90 \\
\hline GHG40EE & 0.08 & 0.15 & & -0.54 & -0.75 \\
\hline GHG40 & 0.62 & 0.69 & 0.54 & & -0.21 \\
\hline Reference & 0.83 & 0.90 & 0.75 & 0.21 &
\end{tabular}

Negative value means that the scenario on the vertical axis is considered worse (lower in the PROMETHEE ranking) than that on the horizontal axis

Table 15 Average distances between scenarios

\begin{tabular}{l|l|l|l|l|l}
\hline Average & GHG40EERES30 & GHG45EERES35 & GHG40EE & GHG40 & Reference \\
\hline GHG40EERES30 & & -0.18 & -0.21 & -0.49 & -0.72 \\
\hline GHG45EERES35 & 0.18 & & -0.02 & -0.30 & -0.53 \\
\hline GHG40EE & 0.21 & 0.02 & & -0.28 & -0.51 \\
\hline GHG40 & 0.49 & 0.30 & 0.28 & & -0.23 \\
\hline Reference & 0.72 & 0.53 & 0.51 & 0.23 & \\
\hline
\end{tabular}




\section{Conclusions}

One of the most crucial issues nowadays is dealing with the climate change repercussions and the increasing energy demand. Towards this direction multiple objectives have been set, through the development of different climate and energy policy scenarios, in order to tackle the several implications and achieve a sustainable development. The aim of this study was to examine which of the defined scenarios could respond adequately to the European region's profile and which could affect positively the living conditions based on the socioeconomic, environmental and energy impacts. Consequently a multi-criteria decision analysis was selected to support in the assessment. More specifically, an integrated approach of PROMETHEE II and Simos procedure has been used, where the strengths of both methodologies are combined in a single MCDA tool, which eventually seems to be fully compatible with the overall methodology. Moreover, several experts were asked to participate in the criteria evaluation so as to perform a sensitivity analysis to ensure the robustness of the results.

All things considered, the methodological approach is based on simple and explicit steps, exploiting criteria and scenarios aligned with the EU's strategy imperatives. The developed model supports the decision-maker also in a distinct implementation, so as to extract in a reasonable time the results.

The most beneficiary scenario in terms of living conditions, according to all the experts' preferences, is the GHG40EERES30. This is considered an acceptable and realistic outcome, since it is the most balanced scenario based on literature and stakeholder consultation. This scenario presents a medium ambition in terms of GHG emission reduction through the carbon pricing (11€/tonne), while it is mainly driven by explicit ambitious energy efficiency policies and pre-set RES target of $30 \%$ that ensure progress by addressing market imperfections and failures. Beyond concrete EE policies, carbon pricing continues to incentivise fuel shifts, energy savings and nonenergy-related emission reductions, and EE polices contribute to higher shares of RES as they reduce total energy consumption as well.

The prevailing scenario is followed by GHG45EERES35, and this in turn is followed by GHG40EE, GHG40 and Reference in that order. It also should be noted that even though the scenario with the $45 \%$ GHG reduction and 35\% RES has the highest targets, it takes the second place because its effects will not be shown up to 2030 but in a 2050 prospect (which is not examined in the present paper). It is also obvious that the "business as usual" will serve no purpose in the next years in view of the increasing energy demand and the intense repercussions of climate change.

As can been seen, the paper has room for improvement by using a different and more integrated approach. The study might be extended by taking into consideration a greater number of alternative scenarios and/or criteria. Moreover a further enhancement could be achieved by involving a greater group of experts to map the diversity of opinions and preferences regarding criteria weights. In that way, it would be possible to extract more concrete and credible suggestions, thus aiding the European effort in the green and sustainable development. 
The added value of this analysis to policymakers is its contribution to plan climate and energy strategies towards a low-carbon transition pathway by using the information of this approach and prioritising the enhancement of the living conditions from a socioeconomic, environmental and energy perspective. The final inference is the significant role of RES and the urgent need for energy efficiency measures in order to achieve the EU targets in parallel with sustainable development.

Acknowledgement The current paper was partially based on the research conducted within the framework of the project "SET-Nav: Navigating the Roadmap for Clean, Secure and Efficient Energy Innovation" that received funding from the European Union's Horizon 2020 research and innovation programme under grant agreement no. 691843.

\section{References}

Brans, J. P., \& Mareschal, B. (2005). PROMETHEE methods. In J. Figueira, S. Greco, \& M. Ehrgott (Eds.), Multiple criteria analysis - state of the art surveys, International series in operations research and management sciences (Vol. 78, pp. 163-195). New York: Springer.

Brans, J. P., Vincke, P., \& Mareschal, B. (1986). How to select and how to rank projects: The Promethee method. European Journal of Operational Research, 24(2), 228-238.

Browne, D., O’Regan, B., \& Moles, R. (2010). Use of multi-criteria decision analysis to explore alternative domestic energy and electricity policy scenarios in an Irish city-region. Energy, 35 (2), 518-528.

Cambridge Econometrics. (2013, October). Employment Effects of selected scenarios from the Energy roadmap 2050. Final report for the European Commission (DG Energy).

Cherni, J. A., Dyner, I., Henao, F., Jaramillo, P., Smith, R., \& Font, R. O. (2007). Energy supply for sustainable rural livelihoods. A multi-criteria decision-support system. Energy Policy, 35(3), 1493-1504.

De Bruyn, S., \& Warringa, G. (2014, March). Review of the Impact Assessment for a 2030 climate and energy policy framework. Delft, CE Delft.

De Vos, R., Van Breevoort, P., Höhne, N., Winkel, T., \& Sachweh, C. (2014, March 17). Assessing the EU 2030 climate and energy targets. A Briefing Paper. Project number: DESNL14683.

Doukas, H., Siskos, E., Psarras, J., Malamatenios, C., Tournaki, S., \& Tsoutsos, T. (2016). Qualification roadmap empowering the Greek building sector workforce in the field of energy. Renewable and Sustainable Energy Reviews, 65, 992-1004.

EC-European Commission. (2009, January 15). Impact assessment guidelines. SEC 92.

EC-European Commission. (2012). Energy Roadmap 2050. Brochure. Accessed from https://ec. europa.eu/energy/sites/ener/files/documents/2012_energy_roadmap_2050_en_0.pdf.

EC-European Commission. (2014, January 22). Communication from the Commission to the European Parliament, the Council, the European Economic and Social Committee and the Committee of the Regions. A policy framework for climate and energy in the period from 2020 to 2030. \{SWD(2014) 15 final $\}$ SWD(2014) 16 final $\}$. Brussels.

EC-European Commission. (2017a). Causes of climate change. Accessed August 28, 2017, from https://ec.europa.eu/clima/change/causes_en.

EC-European Commission. (2017b). Impact assessments. Accessed November 6, 2017, from https://ec.europa.eu/info/law-making-process/planning-and-proposing-law/impact-assess ments_en.

EEA-European Environment Agency. (2016). Energy intensity.

Ernst \& Young. (2014). Macro-economic impacts of the low carbon transition. (C) 2014 Ernst \& Young et Associés; Studio EY France - 1401sG418. 
EU-European Union. (2015). EU ETS handbook. Accessed from https://ec.europa.eu/clima/sites/ clima/files/docs/ets_handbook_en.pdf.

Figueira, J., \& Roy, B. (2002). Determining the weights of criteria in the ELECTRE type methods with a revised Simos' procedure. European Journal of Operational Research, 139(1-2), 317-326.

Flamos, A. (2016). A sectoral micro-economic approach to scenario selection and development: The case of the Greek power sector. Energies, 9, 77.

Goumas, M., \& Lygerou, V. (2000). An extension of the PROMETHEE method for decision making in fuzzy environment: Ranking of alternative energy exploitation projects. European Journal of Operational Research, 123(3), 606-613.

Herva, M., \& Roca, E. (2013). Ranking municipal solid waste treatment alternatives based on ecological footprint and multi-criteria analysis. Ecological Indicators, 25(2013), 77-84.

Kabir, G., Sadiq, R., \& Tesfamariam, S. (2014). A review of multi-criteria decision-making methods for infrastructure management. Structure and Infrastructure Engineering, 10(9), $1176-1210$.

Kalogeras, N., Baourakis, G., Zopounidis, K., \& Dijk, G. (2005). Evaluating the financial performance of agri-food firms: A multicriteria decision-aid approach. Journal of Food Engineering, 70(3), 365-371.

Karakosta, C., \& Askounis, D. (2010). Developing countries' energy needs and priorities under a sustainable development perspective: A linguistic decision support approach. Energy for Sustainable Development, 14(4), 330-338.

Karakosta, C., Doukas, H., \& Psarras, J. (2008). A decision support approach for the sustainable transfer of energy technologies under the Kyoto protocol. American Journal of Applied Sciences, 5(12), 1720-1729.

Karakosta, C., \& Flamos, A. (2016). Managing climate policy information facilitating knowledge transfer to policy makers. Energies, 9, 454.

Karakosta, C., \& Psarras, J. (2012). Fuzzy TOPSIS approach for understanding a country's development priorities within the scope of climate technology transfer. In M. J. Acosta (Eds.), Advances in energy research (Vol. 9, pp. 123-149). Nova Science Publishers. ISBN: 978-161470-485-0.

Loken, E. (2007). Use of multicriteria decision analysis methods for energy planning problems. Renewable and Sustainable Energy Reviews, 11, 1584-1595.

Marinakis, V., Doukas, H., Xidonas, P., \& Zopounidis, C. (2017). Multicriteria decision support in local energy planning: An evaluation of alternative scenarios for the Sustainable Energy Action Plan. Omega, 69, 1-16.

Mohamadabadi, H. S., Tichkowsky, G., \& Kumar, A. (2009). Development of a multi-criteria assessment model for ranking of renewable and non-renewable transportation fuel vehicles. Energy, 34(1), 112-125.

Oskari, L., Risto, L., \& Pekka, S. (2017). Multicriteria evaluation of sustainable energy solutions for Colosseum. Sustainable Cities and Society, 35, 289-297.

Papadelis, S., Flamos, A., \& Psarras, J. (2013). A framework to address uncertainties in energy policy formulation. Energy Sources, Part B: Economics, Planning, and Policy, 8(3), 270-278.

Papapostolou, A., Karakosta, C., \& Doukas, H. (2017). Analysis of policy scenarios for achieving renewable energy sources targets: A fuzzy TOPSIS approach. Energy and Environment, 28 $(1-2), 88-109$.

Papapostolou, A., Karakosta, C., Marinakis, V., \& Flamos, A. (2016). Assessment of RES cooperation framework between the EU and North Africa: A multicriteria approach based on UTASTAR. International Journal of Energy Sector Management (IJESM), 10(3), 402-426.

POLIMP. (2012). D4.2: Socioeconomic impacts of a new climate regime on the EU. Deliverable of the POLIMP project.

Rahman, M. M., Paatero, J. V., Lahdelma, R., \& Wahid, M. A. (2015). Multicriteria-based decision aiding technique for assessing energy policy elements-demonstration to a case in Bangladesh. Applied Energy, 164, 237-244. 
Ribeiro, F., \& Ferreira, P. (2013). Evaluating future scenarios for the power generation sector using a Multi-Criteria Decision Analysis (MCDA) tool: The Portuguese case. Energy, 52, 126-136.

Simos, J. (1990). Evaluer l'impact sur l'environnement: Une approche originale par l'analyse multicritere et la negociation. Lausanne: Presses Polytechniques et Universitaires Romandes.

Streatfield, D. R., \& Markless, S. (2009). What is impact assessment and why is it important? Performance Measurement and Metrics, 10(2), 134-141.

TRANSrisk. (2017). D4.3: Implications of different mitigation portfolios based on stakeholder preferences. Deliverable of the TRANSrisk project.

Volkart, K., Weidmann, N., Bauer, C., \& Hirschberg, S. (2017). Multi-criteria decision analysis of energy system transformation pathways: A case study for Switzerland. Energy Policy, 106, $155-168$.

Wang, J.-J., Jing, Y.-Y., Zhang, C.-F., \& Zhao, J.-H. (2009). Review on multi-criteria decision analysis aid in sustainable energy decision-making. Renewable and Sustainable Energy Reviews, 13, 2263-2278.

Open Access This chapter is licensed under the terms of the Creative Commons Attribution 4.0 International License (http://creativecommons.org/licenses/by/4.0/), which permits use, sharing, adaptation, distribution and reproduction in any medium or format, as long as you give appropriate credit to the original author(s) and the source, provide a link to the Creative Commons license and indicate if changes were made.

The images or other third party material in this chapter are included in the chapter's Creative Commons license, unless indicated otherwise in a credit line to the material. If material is not included in the chapter's Creative Commons license and your intended use is not permitted by statutory regulation or exceeds the permitted use, you will need to obtain permission directly from the copyright holder.

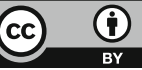

